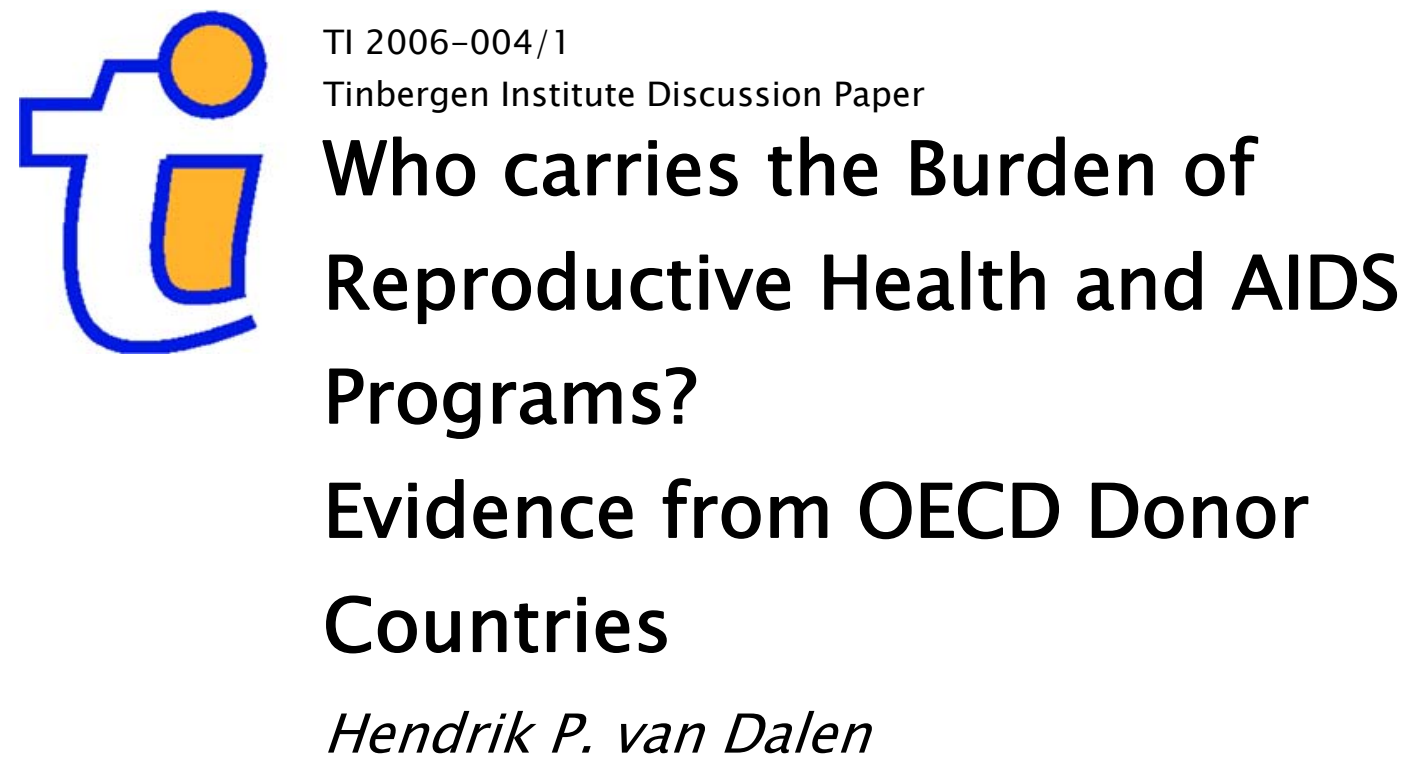

Netherlands Interdisciplinary Demographic Institute (NIDI), Erasmus University Rotterdam, and Tinbergen Institute. 


\section{Tinbergen Institute}

The Tinbergen Institute is the institute for economic research of the Erasmus Universiteit Rotterdam, Universiteit van Amsterdam, and Vrije Universiteit Amsterdam.

Tinbergen Institute Amsterdam

Roetersstraat 31

1018 WB Amsterdam

The Netherlands

Tel.: $\quad+31(0) 205513500$

Fax: $\quad+31(0) 205513555$

Tinbergen Institute Rotterdam

Burg. Oudlaan 50

3062 PA Rotterdam

The Netherlands

Tel.: $\quad+31(0) 104088900$

Fax: $\quad+31(0) 104089031$

Please send questions and/or remarks of nonscientific nature to driessen@tinbergen.nl.

Most TI discussion papers can be downloaded at http://www.tinbergen.nl. 


\title{
Who Carries the Burden of Reproductive Health and AIDS Programs? - Evidence from OECD Donor Countries*
}

\author{
Hendrik P. van Dalen \\ Netherlands Interdisciplinary Demographic Institute (NIDI) \\ P.O. Box 11650 \\ NL - 2502 AR The Hague \\ The Netherlands \\ Email: dalen@nidi.nl \\ Erasmus University Rotterdam \\ Department of Economics, SEOR and Tinbergen Institute \\ P.O. Box 1738 \\ NL-3000 DR Rotterdam \\ The Netherlands
}

December 23, 2005

JEL classification: D74, F35, D78, O19

Key words: Foreign aid, donors, reproductive health, HIV/AIDS, global collective action, OECD

\begin{abstract}
This paper tries to establish who carries the burden in supporting reproductive health and AIDS programs worldwide. The 1994 International Conference of Population and Development (ICPD) in Cairo established goals for the expansion of assistance in matters of reproductive health and AIDS. This global effort has so far not sufficiently been supported by funds and this paper looks at what lies behind the level of funds and the sharing of financial burdens. Panel data on expenditures for population and AIDS activities funded by 21 donor countries for the years 1983-2002 are examined by means of dynamic panel data estimation. On an aggregated scale small donors 'exploit' the large donors: large donors give more resources than their 'fair share', i.e. their income weight in the group of donors. However, this picture is not true for the finance and support for multilateral organizations where every donor country pays its fair share. The exploitation hypothesis is true for the cases of bilateral aid and NGOs. The exploitation model gives however a partial view of what determines the sharing of burdens. To understand burden sharing across countries fully one needs to take account of the most dominant religions in a country, the pro-foreign aid stance of a government and the government size. Donor countries are not much affected in their funding behavior by the state of development of the least developed countries.

* For the purposes of the present paper, data produced within the framework of the UNFPA/UNAIDS/NIDI Resource Flows project have been used (see www.resourceflows.org.). The author wishes to stress that the views expressed in this paper are those of the author and not necessarily those of UNFPA or UNAIDS.
\end{abstract}




\section{Introduction}

What determines the levels of donor government funding in matters of global collective action? The standard retort of a social scientist would be 'altruism', donors care about the welfare of those living in less fortunate circumstances. Informed insiders, like development policy watchers and public choice theorists (cf. Schraeder et al., 1998; Alesina and Dollar, 2000), would be more hesitant in providing the textbook answer. The answer to this question is not as straightforward as it might seem from the outside because in cases of clear collective action, group processes are at work which affect individual donor behavior. Free riding on the efforts of others is thereby not reserved for the study of individual pursuits, it can also be a behavioral response of governments who make some joint effort to provide a global public good, like the war on terrorism or as in the case of the global effort to reduce poverty as spelled out in the Millenium Development Goals.

In this paper the issue of global collective action will be examined for a specific area which is part of the efforts surrounding the Millenium Development Goals, viz. efforts to make reproductive health and HIV/AIDS programs widely accessible, as agreed at the International Conference on Population and Development (ICPD) in Cairo in the summer of 1994. ${ }^{1}$ The intentions of international governments that were involved in drawing up the socalled ICPD Programme of action were quite clear. The donor governments promised to finance one third of the total amount of resource flows that are tied to population activities in developing countries. According to ICPD projections, reproductive health costs in developing countries will likely total 17 billion US dollars in the year 2000 and 21.7 billion US dollars in 2015. So far the contributions by both donor and recipient countries (public and private sector) have lagged far behind these ambitions (cf. Potts et al. 1998, Van Dalen and Reuser, 2005). And the gap between stated ambitions and actual contributions makes one wonder what's behind the lack of funds.

The moral hazard problems tied to global collective action problems are an important candidate for resolving some of the mysteries why donor countries do not live up to their promises or financial pledges (cf. Bulir and Hamann, 2004). The problem which the participants of the Cairo Conference faced, and still face, is a problem not unlike many other foreign aid programs. Population assistance programs pose a collective action problem for the international community as fertility developments in developing countries may pose a tragedy of the commons and the HIV/AIDS pandemic shows that a disease will not stop at the border and threaten the health status of everyone. Many developing nations must rely on other 
nations to provide them with resources and cash to finance population activities, like family planning, investments in reproductive health, AIDS programs and basic research. By increasing the welfare of a recipient country, foreign aid serves as a public good, i.e. an input that produces an output that is both non-excludable and non-rival to all nations interested in the well-being of the recipient. For instance, if the United States helps India and the United Kingdom is also interested in the well being of India it can free ride on the foreign aid efforts of the United States.

A mechanism which offers an explanation for this collective action failure has been described by Olson and Zeckhauser (1966) and summed up in their 'exploitation hypothesis'. Olson and Zeckhauser focused mainly on the financing of military strategic alliances, such as the NATO. Their theory can however be applied to other issues which share this problem and foreign aid is one of them. Essentially their thesis boils down to the following more formal point: if foreign aid is untied, aggregate aid to a recipient represents a fungible resource, since the source of the contribution is immaterial. The recipient's welfare depends then on the sum of aid received from others. Sub-optimality in the supply of foreign aid is then to be expected. E.g., suppose that the recipient's welfare affects the welfare of the would-be donors in a positive manner, then donor contributions will be positively related to the donor's income. Wealthier nations would have a greater desire to contribute aid and so wealthier nations will also bear a larger share of the burden than less well-off nations. In other words, some small country will exploit the benevolence of large countries. Foreign aid would then be suboptimal and some supranational action should be initiated to correct this failure. The manner in which foreign aid is corrected at the supranational level is however crucial as policy initiatives at this level may result in no effect whatsoever if the neutrality theorem applies. If an international agency like UNAIDS or UNFPA supplements a recipient's foreign aid from revenues collected from donor nations, then foreign aid at the supranational level would simply crowd out voluntary foreign aid from donors on a dollar-for-dollar basis (see Sandler, 1992). It remains however an empirical question whether these conditions apply to specific foreign aid problems.

This paper is an empirical examination of the collective action choices made by donors in giving aid to reproductive health activities as envisioned in the ICPD Programme of action. The central question is what determines the sharing of burdens in aid programs? The focus is exclusively turned towards the behavior of donor OECD countries in their choice and financial support of aid channels. I will focus on three different channels through which reproductive health aid flows to developing countries: multilateral organizations (like the UN 
organizations UNFPA and UNAIDS), non-governmental organizations (like Marie Stopes International and International Planned Parenthood Federation), and bilateral aid (governments of developed countries). The three channels of aid for reproductive health assistance differ with respect to the public nature of aid flows. The multilateral aid organizations provide a supranational level of coordination and resembles more closely the pure collective action problem of providing a global public good. The other channels provide services which offer both country-specific (or private) and global public benefits, although again the issues of collective action arise again in this specific context, as the OECD/DAC members promised in 1994 to provide adequate funds according to specific global targets and all countries are therefore bound to live up to that promise. The channels through which aid flows were no matter of deliberation at the Cairo conference.

In order to explore the question we will make use of funding data which the 'resource flows' project group of UNFPA/UNAIDS/NIDI collects. The data includes information on the channels, bilateral, multilateral or non-governmental and covers the period from 1982 to 2002. The set-up of the paper is as follows. First, some stylized facts of burden sharing in the case of reproductive health and HIV/AIDS assistance are presented (section 2), to be followed by a model of donor behavior (section 3) which might shed some light on the driving forces behind donor behavior. In section 4 the theory of donor behavior is put to the test to see which factors in practice are relevant in explaining the stylized facts. Section 5 concludes with some interpretations and implications of the findings.

\section{Some stylized facts of burden sharing}

Before we entertain some thoughts on the behavior of donor governments I will present some facts and figures on the level and structure of funds for reproductive health and HIV/AIDS. To get an overview how funding has shifted we present in Figure 1 the aggregate of primary funds generated by donor countries over the period 1973-2002. In 2002 the total of funds generated by OECD/DAC governments is 2.3 billion US dollars. Over this period a number of events as well as changing views of the population problem have affected funding from donor countries. According to Schindlmayr (2004) one of the factors that account for historical funding trends from primary donors is the occurrence of international population conferences. His reading of the donor funding developments is that donor governments appear to make a special effort to increase funding shortly before and during conference years. 


\section{Figure 1: Level of primary funds population and HIV/AIDS activities (in million US}

dollars), 1973-2002

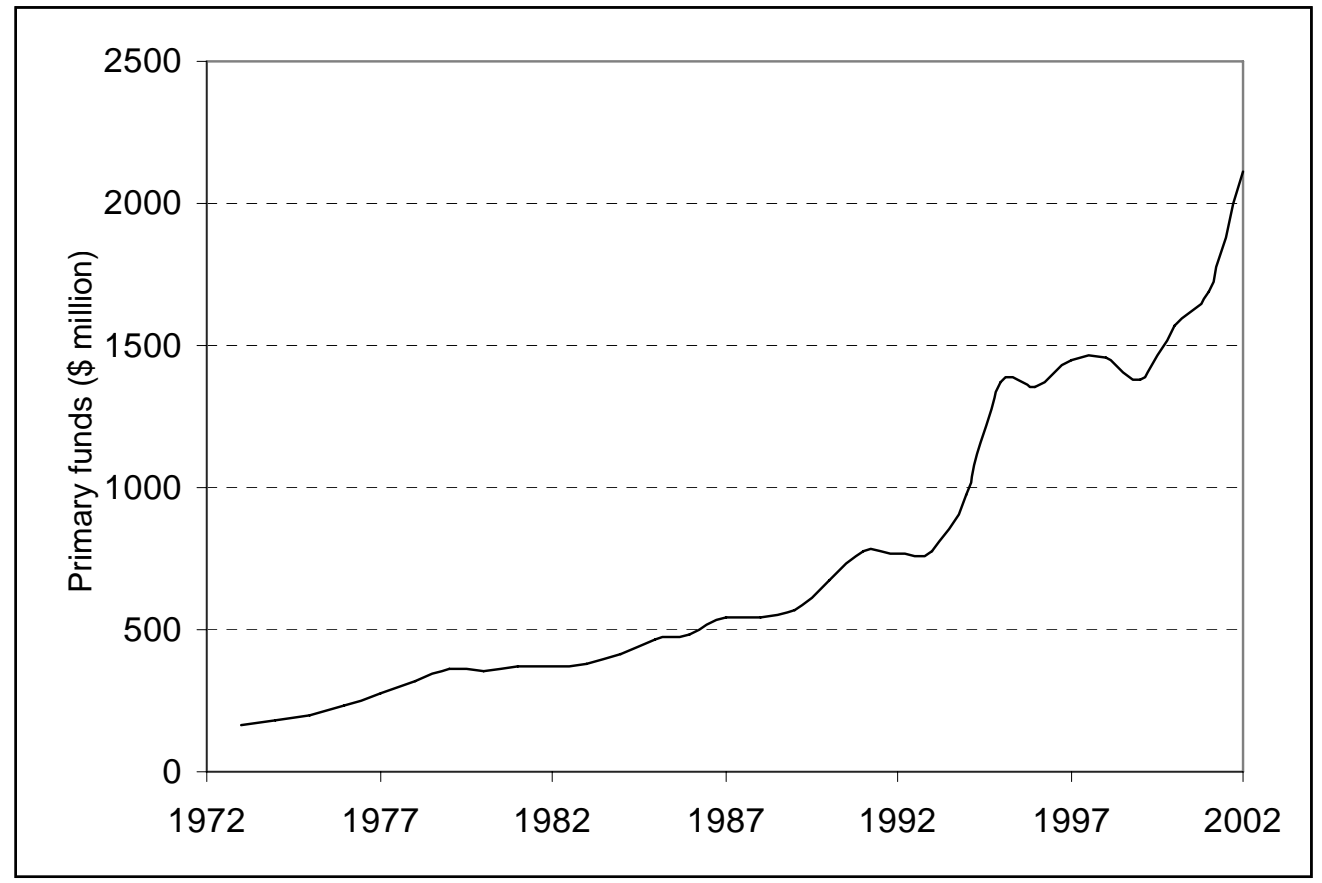

Source: UNFPA/UNAIDS/NIDI

However, funding levels decline in the subsequent years when attention fades away for the population cause. The two important conferences in the period under consideration are the 1984 Mexico City Conference and the 1994 International Conference on Population and Development in Cairo. The latter conference has been marked by some as a fundamental shift in population assistance programs or family planning. However, it remains difficult to disentangle causality in this specific case because the upward shift in funding is in part a consequence of the fact that in 1994 the definition of population assistance was broadened to include reproductive health programs (Bulatao, 1998). ${ }^{2}$ From the year 1996 onwards data have been collected on a more disaggregated level and as one see from Table 1 that the funds generated by OECD/DAC governments are the most important contributors, to be followed at some distance by private foundations, a group of donors which is dominated by funding from the Bill and Melinda Gates foundation. The most dominant trend in these post-Cairo years is the focus on HIV/AIDS, not in the least triggered by the looming AIDS pandemic. 
Table 1: Level of primary funds, various donor types (in million current US dollars)

\begin{tabular}{ccccccc}
\hline Year & $\begin{array}{c}\text { OECD/DAC } \\
\text { government }\end{array}$ & $\begin{array}{c}\text { Private } \\
\text { foundations }\end{array}$ & $\begin{array}{c}\text { Bank Grants } \\
\text { development banks }\end{array}$ & UN system & NGO & Total funds \\
\hline & $(1)$ & $(2)$ & $(3)$ & $(4)$ & $(5)$ & Sum (1) to (5) \\
1996 & 1369.1 & 92.4 & 7.8 & 18.0 & 48.1 & 1535.4 \\
1997 & 1529.9 & 62.8 & 9.1 & 49.1 & 42.9 & 1693.8 \\
1998 & 1538.8 & 72.5 & 10.4 & 34.5 & 51.1 & 1707.3 \\
1999 & 1411.1 & 175.6 & 9.2 & 31.4 & 64.1 & 1691.4 \\
2000 & 1597.7 & 250.7 & 0.8 & 77.3 & 48.1 & 1974.6 \\
2001 & 1719.7 & 201.6 & 3.2 & 96.1 & 39.1 & 2059.7 \\
2002 & 2313.9 & 460.1 & 2.0 & 31.4 & 70.3 & 2877.7 \\
\hline
\end{tabular}

Source: Van Dalen and Reuser (2005)

To shed some light on the central issue of this paper - burden sharing - Table 2 presents the relative shares of OECD/DAC countries in population and HIV/AIDS activities by aid channel per country and Figure 2 presents the allocation of population aid by aid channel in the aggregate.

Figure 2: Allocation of population and HIV/AIDS assistance across aid organization types, 1982-2003

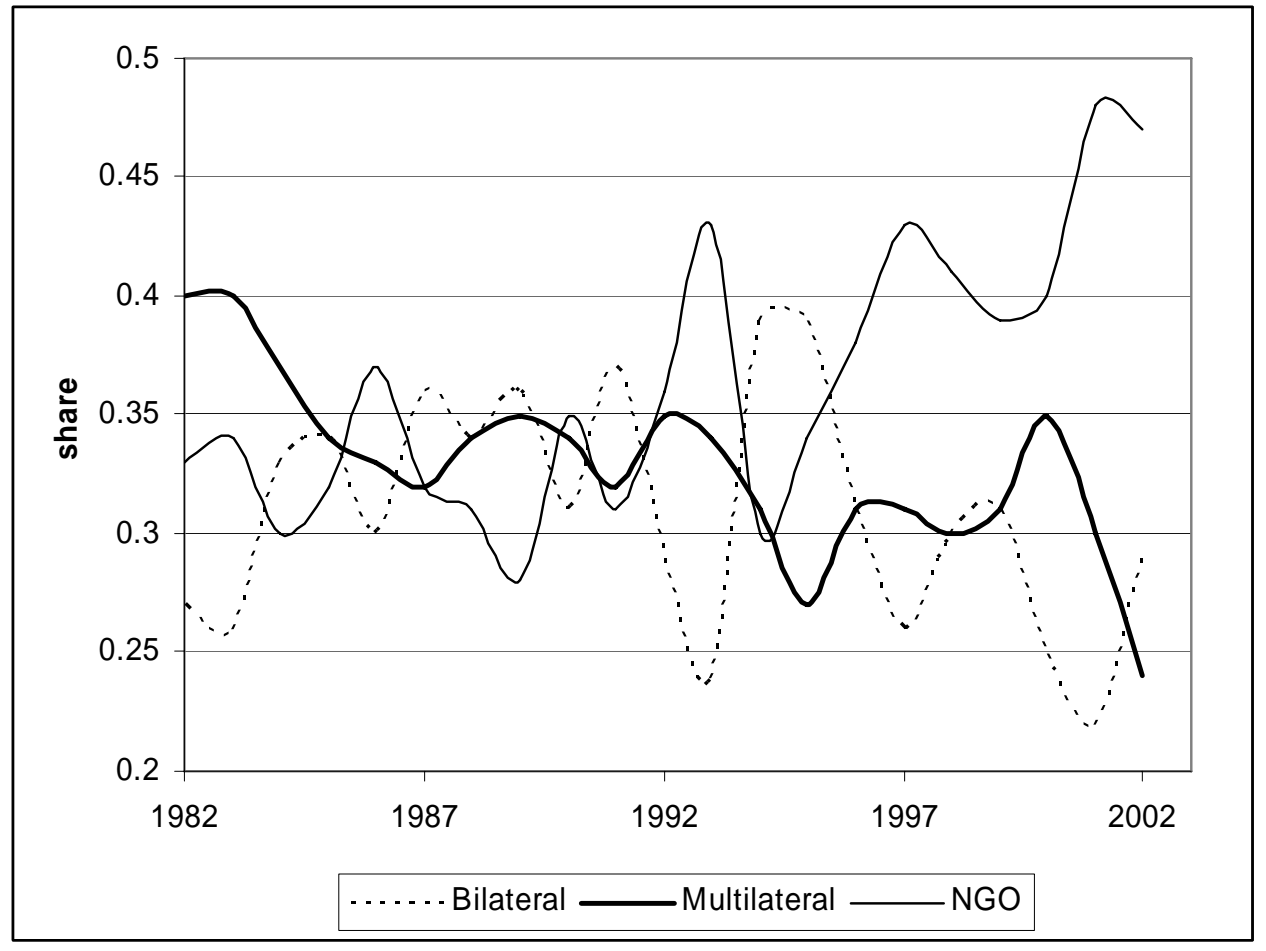


Bilateral channel includes funds that flow directly from donor governments to recipient country governments. The multilateral channel includes general funds that are not earmarked for specific population activities, which multilateral organizations receive from donor governments. The NGO channel comprises funds from foundations and general contributions to NGOs active in the field of population and bilateral expenditures for specific population activities that are executed by NGOs (UNFPA, 2001). The most striking aspect of Figure 2 is the fact that funding through NGOs is the dominant organizational form since 1996, whereas the funds allocated through multilateral organizations has steadily declined from 40 percent in 1982 to 24 percent in 2002 .

In Table 2 one can see which country is responsible for this switch. The United States is the most dominant party in the case of reproductive health and HIV/AIDS funding (cf. Van Dalen and Reuser, 2005) and this simple observation affects the aggregate outcomes to a large extent. As one can see from Table 2 the US has switched from bilateral funding (from a share of 71 percent in 1983-94 to a share of 42 percent in1995-2002) to funding through NGOs (increasing its share from 69 percent to 76 percent). However, each country seems to tell a different story. E.g., Germany has increased its world-wide share in bilateral funding by 10 percentage points (over the two decades), Japan has decreased its share in multilateral funding with almost 8 percentage points; this decrease is almost neutralized by the funding efforts of the Netherlands. The Netherlands is the only country which has increased its funds for all channels, but by and large its interests focus on multilateral agencies and despite its size it is the number one financier of multilateral agencies in population and HIV/AIDS.

What is clear from examining the divergence and development in these aggregate figures is that the sample of countries is split between a slight majority (12 countries) which gives less than their fair share based on GDP, while a slight minority ( 9 countries) are willing to give more than their fair share to fund reproductive health activities. Another stylized fact which needs some explanation is the fact that over time two third of the sample of countries raised their aid share over time, while a third has decreased its share. 
Table 2: Relative shares of donor countries in population activities and GDP (percentages), 1983-2002

\begin{tabular}{|c|c|c|c|c|c|}
\hline & Total primary funds & Multilateral agencies & NGO funding & Bilateral funds & Nominal GDP \\
\hline \multicolumn{6}{|l|}{ Australia } \\
\hline 1983-1994 & 0.86 & 1.10 & 0.43 & 1.09 & 1.85 \\
\hline $1995-2002$ & 1.93 & 1.44 & 0.97 & 3.82 & 1.70 \\
\hline $1983-2002$ & 1.29 & 1.24 & 0.65 & 2.18 & 1.79 \\
\hline \multicolumn{6}{|l|}{ Austria } \\
\hline 1983-1994 & 0.05 & 0.14 & 0.00 & 0.02 & 0.89 \\
\hline $1995-2002$ & 0.09 & 0.22 & 0.01 & 0.06 & 0.91 \\
\hline $1983-2002$ & 0.07 & 0.17 & 0.00 & 0.03 & 0.90 \\
\hline \multicolumn{6}{|l|}{ Belgium } \\
\hline 1983-1994 & 0.24 & 0.55 & 0.02 & 0.14 & 1.07 \\
\hline $1995-2002$ & 0.90 & 1.93 & 0.22 & 0.84 & 1.08 \\
\hline $1983-2002$ & 0.50 & 1.11 & 0.10 & 0.42 & 1.07 \\
\hline \multicolumn{6}{|l|}{ Canada } \\
\hline 1983-1994 & 4.67 & 5.50 & 3.95 & 4.52 & 3.38 \\
\hline $1995-2002$ & 2.53 & 3.83 & 1.78 & 2.24 & 2.79 \\
\hline $1983-2002$ & 3.81 & 4.83 & 3.08 & 3.61 & 3.15 \\
\hline \multicolumn{6}{|l|}{ Denmark } \\
\hline 1983-1994 & 2.91 & 6.51 & 2.09 & 0.03 & 0.74 \\
\hline $1995-2002$ & 3.51 & 8.26 & 2.31 & 0.45 & 0.74 \\
\hline $1983-2002$ & 3.15 & 7.21 & 2.17 & 0.20 & 0.74 \\
\hline \multicolumn{6}{|l|}{ Finland } \\
\hline $1983-1994$ & 1.84 & 4.85 & 0.17 & 0.42 & 0.64 \\
\hline $1995-2002$ & 1.39 & 3.56 & 0.32 & 0.65 & 0.54 \\
\hline $1983-2002$ & 1.66 & 4.33 & 0.23 & 0.51 & 0.60 \\
\hline \multicolumn{6}{|l|}{ France } \\
\hline 1983-1994 & 0.53 & 0.33 & 1.04 & 0.17 & 6.63 \\
\hline $1995-2002$ & 1.29 & 0.89 & 1.24 & 1.78 & 6.19 \\
\hline $1983-2002$ & 0.83 & 0.55 & 1.12 & 0.81 & 6.45 \\
\hline \multicolumn{6}{|l|}{ Germany } \\
\hline 1983-1994 & 6.64 & 10.61 & 1.96 & 7.02 & 9.28 \\
\hline $1995-2002$ & 7.63 & 6.84 & 1.12 & 17.83 & 9.14 \\
\hline $1983-2002$ & 7.03 & 9.10 & 1.63 & 11.34 & 9.22 \\
\hline \multicolumn{6}{|l|}{ Ireland } \\
\hline $1983-1994$ & 0.02 & 0.07 & 0.00 & 0.00 & 0.27 \\
\hline $1995-2002$ & 0.28 & 0.30 & 0.04 & 0.39 & 0.39 \\
\hline $1983-2002$ & 0.24 & 0.28 & 0.04 & 0.35 & 0.37 \\
\hline \multicolumn{6}{|l|}{ Italy } \\
\hline $1983-1994$ & 0.81 & 2.16 & 0.11 & 0.09 & 5.59 \\
\hline $1995-2002$ & 0.76 & 1.56 & 0.13 & 0.89 & 4.98 \\
\hline $1983-2002$ & 0.79 & 1.92 & 0.12 & 0.41 & 5.35 \\
\hline
\end{tabular}




\begin{tabular}{|c|c|c|c|c|c|}
\hline \multicolumn{6}{|l|}{ Japan } \\
\hline 1983-1994 & 9.95 & 21.89 & 4.15 & 3.40 & 18.85 \\
\hline $1995-2002$ & 7.26 & 14.21 & 4.27 & 4.50 & 19.26 \\
\hline $1983-2002$ & 8.88 & 18.82 & 4.20 & 3.84 & 19.01 \\
\hline \multicolumn{6}{|l|}{ Luxembourg } \\
\hline 1983-1994 & 0.06 & 0.17 & 0.00 & 0.00 & 0.07 \\
\hline $1995-2002$ & 0.27 & 0.25 & 0.04 & 0.67 & 0.08 \\
\hline $1983-2002$ & 0.23 & 0.23 & 0.03 & 0.54 & 0.08 \\
\hline \multicolumn{6}{|l|}{ Netherlands } \\
\hline 1983-1994 & 4.73 & 11.37 & 1.15 & 1.47 & 1.66 \\
\hline $1995-2002$ & 8.46 & 18.94 & 2.18 & 6.51 & 1.71 \\
\hline $1983-2002$ & 6.22 & 14.40 & 1.56 & 3.48 & 1.68 \\
\hline \multicolumn{6}{|l|}{ New Zealand } \\
\hline 1983-1994 & 0.08 & 0.12 & 0.10 & 0.02 & 0.26 \\
\hline $1995-2002$ & 0.13 & 0.25 & 0.14 & 0.01 & 0.25 \\
\hline $1983-2002$ & 0.10 & 0.17 & 0.11 & 0.02 & 0.26 \\
\hline \multicolumn{6}{|l|}{ Norway } \\
\hline 1983-1994 & 6.56 & 11.04 & 3.25 & 5.40 & 0.67 \\
\hline $1995-2002$ & 3.77 & 10.09 & 1.61 & 0.42 & 0.70 \\
\hline $1983-2002$ & 5.44 & 10.66 & 2.59 & 3.40 & 0.68 \\
\hline \multicolumn{6}{|l|}{ Portugal } \\
\hline 1983-1994 & 0.01 & 0.02 & 0.00 & 0.00 & 0.44 \\
\hline $1995-2002$ & 0.03 & 0.06 & 0.00 & 0.05 & 0.48 \\
\hline $1983-2002$ & 0.03 & 0.05 & 0.00 & 0.05 & 0.48 \\
\hline \multicolumn{6}{|l|}{ Spain } \\
\hline 1983-1994 & 0.07 & 0.21 & 0.00 & 0.00 & 2.53 \\
\hline $1995-2002$ & 0.44 & 0.56 & 0.03 & 0.99 & 2.56 \\
\hline $1983-2002$ & 0.36 & 0.49 & 0.02 & 0.79 & 2.55 \\
\hline \multicolumn{6}{|l|}{ Sweden } \\
\hline 1983-1994 & 5.20 & 8.04 & 6.55 & 0.89 & 1.27 \\
\hline $1995-2002$ & 3.99 & 6.46 & 2.31 & 3.86 & 1.06 \\
\hline $1983-2002$ & 4.72 & 7.40 & 4.86 & 2.08 & 1.19 \\
\hline \multicolumn{6}{|l|}{ Switzerland } \\
\hline 1983-1994 & 0.76 & 2.14 & 0.07 & 0.04 & 1.24 \\
\hline $1995-2002$ & 1.20 & 2.61 & 0.43 & 0.82 & 1.15 \\
\hline $1983-2002$ & 0.96 & 2.39 & 0.22 & 0.37 & 1.20 \\
\hline \multicolumn{6}{|l|}{ UK } \\
\hline 1983-1994 & 5.31 & 6.14 & 5.67 & 4.29 & 5.39 \\
\hline $1995-2002$ & 7.79 & 8.95 & 4.90 & 11.10 & 5.90 \\
\hline $1983-2002$ & 6.30 & 7.27 & 5.36 & 7.01 & 5.59 \\
\hline \multicolumn{6}{|l|}{ USA } \\
\hline 1983-1994 & 48.83 & 7.44 & 69.31 & 71.00 & 37.44 \\
\hline $1995-2002$ & 46.43 & 8.80 & 75.96 & 42.13 & 38.41 \\
\hline $1983-2002$ & 47.87 & 7.98 & 71.97 & 59.45 & 37.82 \\
\hline
\end{tabular}




\section{Theory of Donor Behavior}

To understand the stylized facts one has try to see donor behavior as being driven by two factors: (1) the internal driving forces of a donor, irrespective of what others give; and (2) the strategic interaction forces that play a role in financing or providing public goods. It is the latter aspect which needs some further exposition. Thinking about donor behavior with respect to the ICPD agenda revolves essentially around the mechanisms of collective action. The question that concerns donor governments is not a novel issue as it turns on the fundamental problem of the theory of international collective action (Olson and Zeckhauser, 1966) where a global collective good has to be financed by contributions of the community. Olson and Zeckhauser focused mainly on the financing of a military strategic alliance, such as NATO. The main conclusion was that due to specific externalities tied to such an alliance big countries, such as the US, contributed disproportionately (in terms of GDP) compared to the smaller countries.

Their theory can easily be applied to the questions of foreign aid as there are numerous multilateral organizations, particularly within the UN-system, which have been established to accommodate the needs of the developing world. In this paper we want to focus on the question of foreign aid directed at family planning and reproductive health programs. We assume that each and every OECD/DAC member cares about the level of welfare in the least developed countries. ${ }^{3}$ In order to cope with the problem of widespread poverty donor countries form an alliance - the Cairo conference members - which promises to finance a public good $Q$, which in our case boils down to a level of public (reproductive) health care. Each of the $n$ members of the alliance allocates part of its national income $I$ to private goods $y_{\mathrm{i}}$ and a contribution to the global public good $Q: q_{i}$. Let's assume for the sake of the argument that all decisions are made by the national government (often the ministry of foreign affairs). The maximization problem of the government can then be represented as the objective of maximizing national welfare $U^{i}$ :

$$
U^{i}=U^{i}\left(y^{i}, q^{i}+Q_{-i}, T\right)
$$

where: 


$$
Q_{-i}=\sum_{j \neq i}^{n} q_{j}
$$

The threat variable $T$ in this case amounts to the poverty or welfare in general in the developing world. The threat being that increasing income inequality in the world will reinforce migration tendencies or it will put pressure on $\mathrm{OECD} / \mathrm{DAC}$ countries to provide more development assistance, just like the Millennium Development Goals entices OECD countries to increase development assistance to slash poverty rates by half by the year 2015 . The threat is in this set-up common to all countries although each and every member can interpret the threat differently. In general one can say that when poverty rises in the developing world this will lead to a decrease in welfare (i.e. $\partial U^{i} / \partial T<0$ ). In maximizing the welfare objective donor governments have to obey their budget constraint:

$$
I^{i}=y^{i}+p q^{i}
$$

where the private good is the numéraire and hence its price is 1 and the price of the health care package needed to finance activities in, e.g., family planning, reproductive health care and HIV/AIDS is $p$. To simplify matters we assume that each donor faces the same price, hence there can be no comparative advantage in providing aid. The general insight from this particular type of collective action problem is that the Nash level of foreign aid is less than the Pareto efficient level of aid. In other words, the 'market' for foreign aid fails in a decentralized setting. In the Nash equilibrium the donor government chooses a level of spending on foreign aid and private goods subject to its budget constraint and given the best response level of other allies, $Q_{-\mathrm{i}}$. The reaction function of donor $i$ can therefore be written as:

$$
q^{i}=q^{i}\left(p, I^{i}, Q_{-i}, T\right)
$$

In order to produce the Pareto-efficient outcome each and every ally should choose a level of foreign aid so that the sum of the marginal rates of substitution between aid and the private good equals the price of aid $p$. This would be the solution of a global decision maker who could oversee the willingness of every participant to contribute to the global public good. In the Nash case each donor equates its own marginal rate of substitution with the price of 
population aid and thereby donates too few resources. The latter insight is particularly relevant in the context of ICPD agenda.

The model spelled out above sheds some light on the choice of funding in the case of a strategic alliance and the ideal organization to circumvent the 'market failures' of giving would be to centralize all donor decisions. A multilateral organization would be the practical translation that comes close to this ideal. Of course, with the construction of a multilateral organization new organizational problems and costs arise which may well counter the benefits of centralization. In the case of foreign aid for reproductive health or HIV/AIDS, governments can choose between two other types of aid channels: (i) aid can be directed to NonGovernmental Organizations (NGOs), or (ii) governments can use bilateral aid channels and hence transfer money directly to national governments which in their view are in need of aid. All channels differ with respect to the publicness of benefits and the publicness in decision making (see Kaul and Mendoza, 2003). The tacit assumption made in the above model of strategic alliances is that every contributor to a multilateral organization is in agreement with the allocation of funds to various reproductive health categories, or how to distribute the benefits of aid to all those concerned. This may be a major reason for some countries dislike multilateral organizations and prefer bilateral aid or NGOs with a profile that coincides with their preferences. In case a country does not want to depend on the efforts of others - and in other words, completely erode the possibilities for free riding in finance - bilateral aid is the option which allows some sovereignty. The response level of other allies, $Q_{-i}$ is therefore by definition irrelevant for choosing the level of funding: $\partial q^{i} / \partial Q_{-i}=0$.

The choice for a particular NGO is a case in between multilateral organization and bilateral aid as one can benefit from the economies of scale, internalized by the NGO, and still choose an organization that fits the profile or preferences of the donor. Most donors may not have the funds to execute bilateral programs and can therefore not neglect the efforts of others if they want to achieve goals that are in line with the agenda set by the participants of the Cairo conference. They are dependent on others because of their small size and they have to take into account the nature of the aggregation technologies which apply to specific public goods (Sandler and Arce, 2002). In the production of the public good it matters whether we are dealing with a simple summation technology - in which each unit contributed to a public good adds identically and additively to the overall level available to all (the default assumption made in the above model). However, one would expect in the case of reproductive health a best shot technology - the global public good is determined by the largest 
contribution among participating countries; or a weakest link technology - the smallest contribution determines the quantity of the public good.

\section{Putting the Theory to the Test}

The previous model highlights the elements which can be relevant in explaining the behavior of a typical donor government and the question of sharing the burden. To highlight the most important driving forces in sharing the burden, the following equation is estimated by means of dynamic panel estimation:

$$
\log \frac{D_{i t}}{\sum D_{i t}}=\alpha \log \frac{G D P_{i t}}{\sum G D P_{i t}}+\beta \log Q_{-i}+\varphi T_{i t}+\sum_{j} \gamma_{i j} \log X_{i j t}+\varepsilon_{i t}
$$

The share of funds $D_{\mathrm{it}}$ in the total of funds is explained four type of variables (1) ability to pay, the first term on the right-hand side; (2) the contributions made by others $Q_{-i}$; (3) a threat variable $T_{\mathrm{it}}$; and (4) the characteristics of the donor country (summed up by $j$ variables $\left.X_{\mathrm{ijt}}\right)^{5}$, to approximate (country-)specific preferences or technologies in the giving of aid. It is assumed that every country faces the same price of offering reproductive health aid and hence this variable is not included as an explanatory variable.

\section{Data}

To explain the behavior of donors in funding over time we have pooled the experiences of the 21 countries and employed the method of dynamic panel estimation. ${ }^{6}$ The panel is not balanced as not every country has observations for the period 1982-2002. To be specific, Ireland, Luxembourg, Spain, and Portugal are latecomers to the pool of donors and for specific aid channels like bilateral aid and NGO some countries the years in which no aid is provided are left out of our sample. Only non-negative numbers are used to examine donor behavior. The descriptive statistics are presented for the entire sample of countries in Table 3 .

Among the most important potential explanatory factors are income and income distribution of a country, the pro-foreign assistance stance of some countries as measured by the share of GDP allocated to official development assistance (ODA, excluding population assistance), the donor expenditures of other countries (lagged with one period), the business cycle state of an economy as measured by the level of unemployment, the threat of a widening gap in human development (as approximated by the Human Development Index), the 
influence of particular religions in a country, and the political ideology of the ruling government (as collected by Beck et al. 2001).

Table 3: Descriptive statistics, 1983-2002

\begin{tabular}{|c|c|c|c|c|c|}
\hline Variable & $\mathrm{Obs}^{\mathrm{a}}$ & Mean & Std. Dev. & Min & Max \\
\hline \multicolumn{6}{|l|}{ Group shares within OECD/DAC } \\
\hline Total primary funds & 293 & 0.059 & 0.112 & $0.000^{\mathrm{b}}$ & 0.615 \\
\hline Bilateral & 220 & 0.080 & 0.172 & $0.000^{\mathrm{b}}$ & 0.827 \\
\hline Multilateral & 286 & 0.058 & 0.062 & $0.000^{\mathrm{b}}$ & 0.290 \\
\hline NGO & 235 & 0.076 & 0.185 & $0.000^{\mathrm{b}}$ & 0.805 \\
\hline GDP & 293 & 0.056 & 0.094 & 0.001 & 0.460 \\
\hline \multicolumn{6}{|l|}{ Average share $t-1$ : } \\
\hline Others total primary funds & 293 & 0.049 & 0.010 & 0.032 & 0.076 \\
\hline Others bilateral & 220 & 0.016 & 0.004 & 0.004 & 0.030 \\
\hline Others multilateral & 286 & 0.016 & 0.003 & 0.011 & 0.029 \\
\hline Others NGO & 235 & 0.017 & 0.006 & 0.006 & 0.030 \\
\hline \multicolumn{6}{|l|}{ Level of: } \\
\hline Total Primary funds & 293 & 55817.3 & 107801.1 & 124.8 & 667086.0 \\
\hline Bilateral & 220 & 23645.6 & 47708.3 & 9.1 & 266834.4 \\
\hline Multilateral & 286 & 17769.1 & 19081.8 & 24.2 & 116400.9 \\
\hline NGO & 235 & 25844.5 & 70783.6 & 12.1 & 465163.4 \\
\hline GDP level (1995 prices) & 293 & 1175124 & 1884571 & 17826.6 & 8955100 \\
\hline ODAGDP (excl. Population funds) \% & 293 & 0.444 & 0.254 & 0.072 & 1.183 \\
\hline HDI donor i & 293 & 0.918 & 0.014 & 0.882 & 0.971 \\
\hline HDI LDC & 293 & 0.401 & 0.026 & 0.358 & 0.445 \\
\hline GDP per capita (1995 prices) & 293 & 25721.8 & 7805.8 & 11119.3 & 58464.2 \\
\hline Gini coefficient & 293 & 29.380 & 4.347 & 24.7 & 36.8 \\
\hline Unemployment (\%) & 293 & 7.630 & 3.709 & 1.6 & 23.9 \\
\hline $\begin{array}{l}\text { Government size (government } \\
\text { consumption/GDP) }\end{array}$ & 293 & 20.624 & 3.544 & 13.3 & 29.4 \\
\hline Presence left wing government & 293 & 0.430 & 0.496 & 0 & 1 \\
\hline EU-member & 293 & 0.532 & 0.500 & 0 & 1 \\
\hline Catholic religion among top 2 religion & 293 & 0.693 & 0.462 & 0 & 1 \\
\hline Lutheran religion among top 2 religion & 293 & 0.246 & 0.431 & 0 & 1 \\
\hline Protestant religion among top 2 religion & 293 & 0.625 & 0.485 & 0 & 1 \\
\hline
\end{tabular}

(a) The sample is not balanced and the number of observations varies per aid channel and in this table the statistics are presented in line with the outcomes of Table $4 \mathrm{~b}$ and 5.

(b) These values are positive, but extremely small.

The explanatory variables come from different sources. The level of GDP (total and per capita), Official Development Assistance (excluding population assistance, expressed as a percentage of GDP), government size (as measured by general government final consumption expenditure as percentage of GDP), unemployment rate (as percentage of labor force) are all extracted from the World Bank Development Indicators (edition 2004). The ODA variable is corrected for the influence of population aid by subtracting funds to population and AIDS 
programs from the level of ODA. The Human Development Index is a weighted average of income, literacy and life expectancy, with weights as described in Human Development Reports of the UN (WHO, 2004), but with data from the World Development Indicators. The income inequality measures (i.c. Gini indices) come from the Luxembourg Income Study which reports at irregular intervals the state of income inequality in a host of OECD countries. ${ }^{7}$ All the previously stated variables are defined in logarithmic form so the relevant coefficients can be more easily interpreted as elasticities. The religion dummies apply to the presence of (Roman) Catholic, Lutheran or Protestant religion belonging to the two most dominant religions in each country as registered by UNESCO $(2000) .{ }^{8}$ Finally, we have included membership of the European Union as an explanatory dummy because we expect that some countries will take account of the fact that the European Union is a separate contributor to the ICPD agenda and changes in donor funding from the EU can have some effect on funding behavior of individual EU members. To gauge the effect of the Mexico City Policy of the United States we use two types of dummy variables, which are explained at the appropriate point in the text.

\section{Sharing of burdens}

The standard measure to reflect on the burden-sharing capacity of a donor country is the share of GDP which is devoted to financing population activities as envisioned in the Programme of action. Olsen and Zeckhauser (1966) were the first to check whether there exist in the practice of the NATO some form of 'exploitation' by the small countries of the large countries within a defense alliance. The Olson and Zeckhauser test is restricted to within-ally burden sharing (measured as the contribution to collective action in relation to the contributor's ability to pay). As pointed out by Sandler and Hartley (2001) it would be more appropriate to test to the idea of burden sharing by using an among-ally indicator. Such a measure would boil down to the contributor's share of the total contribution by all members, as shown in Table 2.The following null hypothesis is relevant: each donor gives money that is equal to its share in total GDP of all donors. To the test the burden sharing hypothesis we follow the approach of Addison et al. (2004) who examined burden sharing in the case of multilateral foreign aid and found some traces of 'reverse exploitation': the small countries support multilateral agencies disproportionately. The ability to pay is the starting point for the estimation exercise, but given the fact that is difficult to really pin down the case of exploitation the focus in this section will be on shedding light on revealed burden sharing in terms of the ability to pay as well as other factors. The ability to pay is approximated by the share of GDP in the group of 
OECD/DAC countries. If each and every country carries the burden of financing a pure public good in line with its ability to pay, the coefficient $\alpha$ (estimated in equation 5) would be equal to one and if we assume that everyone has the same capabilities and preferences the effect of other variables would be negligible. The 'exploitation hypothesis' would be a case of $\alpha>1$, and 'reverse exploitation' would, of course, boil down to the case of $\alpha<1$. Casual observation of Table 2 gives the impression that the case of 'fair' burden sharing $(\alpha=1)$ is rarely the case: on an aggregate scale twelve countries give less than their income share and nine give more than their income share. However, within the various aid channels the picture is far more varied and less clear-cut. Estimating a naive version of equation (5) would give a rough idea of how burdens are shared in the world (see Table 4a).

Table 4a: Explaining Burden Sharing in Reproductive Health Programs, by Aid Channels ${ }^{\mathrm{a}}$, 1983-2002

\begin{tabular}{lcccc}
\hline \multicolumn{4}{c}{ Share aid of country i in the total aid flow: } \\
\hline & $\begin{array}{c}(1) \\
\text { Total of } \\
\text { primary funds }\end{array}$ & $\begin{array}{c}(2) \\
\text { Multilateral }\end{array}$ & NGO funding & Bilateral funding \\
Income & & & & \\
Share GDP & $0.94^{* *}$ & $0.77^{* *}$ & $0.95^{* *}$ & $0.98^{* *}$ \\
& $(0.05)$ & $(0.06)$ & $(0.06)$ & $(0.11)$ \\
Constant & $-0.71^{* *}$ & $-1.07^{* *}$ & $-1.08^{* *}$ & -0.45 \\
& $(0.20)$ & $(0.28)$ & $(0.35)$ & $(0.44)$ \\
\hline Loglikelihood & -129.76 & -138.17 & -254.66 & -314.84 \\
$\mathrm{~N}$ & 375 & 383 & 304 & 285 \\
\hline
\end{tabular}

(a) FGLS regression with country-specific AR(1) processes and controlling for heteroskedasticity. Standard errors are between brackets below the coefficients, $* *$ denotes significance at $<1 \%$ level.

The estimation results clearly demonstrate that 'large' countries are exploiting the 'small' countries, although it must be said that the coefficients for $\alpha$ are close to one in the case of NGO funding and bilateral aid. In short, for the latter two categories one must conclude that burdens are shared more or less in line with one's ability to pay. Of course, the question is whether this naive picture is robust.

The (reverse) 'exploitation' interpretation would be applicable if the public good, i.c. reproductive health care, would be a pure global public good. As mentioned before, the assumption of a global public good would be valid if there are no individual-specific side benefits to the provision of foreign aid. In that respect, the term 'exploitation' is something of 
Table 4b: Explaining Burden Sharing in Reproductive Health Programs, by Aid Channels, 1983-2002

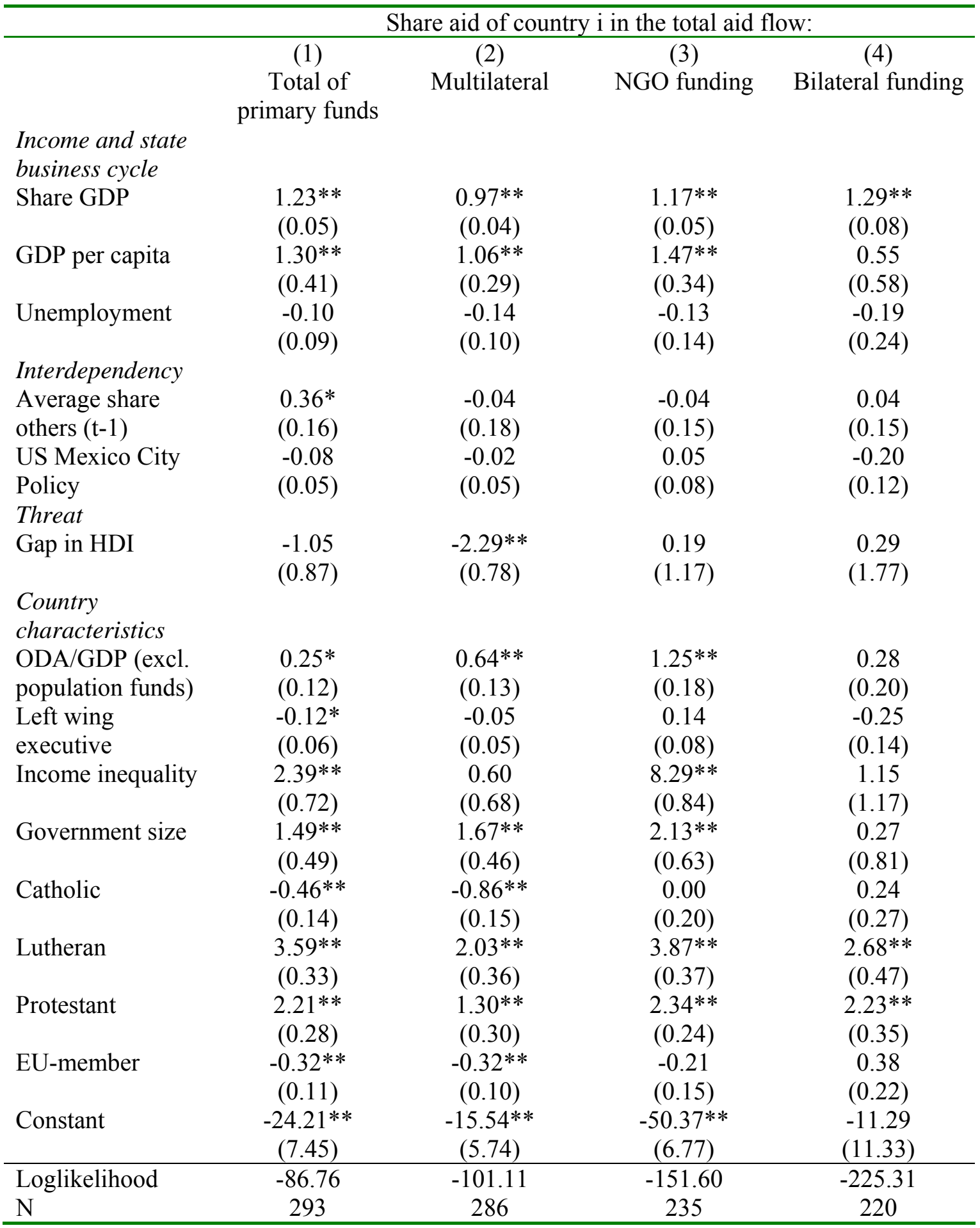

(a) FGLS regression with country-specific AR(1) processes and controlling for heteroskedasticity. Standard errors are between brackets below the coefficients, ${ }^{* *}$ denotes significance at $<1 \%$ level; and $*$ denotes significance at $<5 \%$ level. 
a misnomer because it does not necessarily signify exploitation of the big by the small countries. It could very well be the case that governments act in accordance with the principle of comparative advantages or economies of scale or they derive benefits from 'giving' based on ideological preferences or religious principles, hence making the inclusion of variables which control for such characteristics necessary. Table $4 \mathrm{~b}$ gives a more complete picture by not only estimating the GDP share but also the interaction with other countries, the threat of poverty, and the individual characteristics which include not only preferences about the income inequality, and the political ideology of the ruling government.

Table $4 \mathrm{~b}$ presents a picture that differs markedly from the naïve model of Table 4a. The results show unambiguously that large countries predominantly choose the channels of NGOs and bilateral aid. Small countries favor the multilateral organizations but the parameter $\alpha$ is close to one and certainly not so small as the parameter presented in Table 4a. The latter finding is in line with what Addison et al. (2004) report who reviewed the exploitation hypothesis for multilateral aid agencies. They find clear signs of 'reverse exploitation', where donor governments of small economies carry a disproportionately large share of the funding burdens of multilateral agencies. However, the reverse exploitation hypothesis does not give an accurate picture when they focus on UN and EC agencies: the parameter $\alpha$ is close to one. In that respect, their specific findings are in line with the present study.

\section{Interaction with others}

The presence of other donors can have an effect on behavior it remains an open question in which direction the interaction affects donations. There is a literature on public goods experiments (cf. Gächter and Fehr, 1999; Andreoni and Petrie, 2004) in which individual donations are positively affected by what others give, as long as these donations are 'in the open'. Donors value how their contribution relates to some 'fair' standard, which is in turn related to what others give. However, in the context of a public good one can also expect a negative sign as donors could possibly care only about the level of public good $Q$ and when someone else already funds the largest part of this production costs, the donor can withhold (part) of the intended funds. In other words: $\partial q^{i} / \partial Q_{-i}<0$. Table $4 \mathrm{~b}$ clearly shows that none of these effects are clearly present in the donor statistics and there is only one conclusion possible: donor countries are not affected by what others give.

Another variable which measures interaction is an element that is specific to the policy context of reproductive health, viz. the Mexico City Policy of the US or as it is called by some the Global Gag Rule. This policy - initiated by President Ronald Reagan, and applied also by 
presidents Bush senor and junior - boils down to the policy measure to deny foreign organizations receiving U.S. family planning assistance the right to use their own, non-U.S. funds to either engage in any abortion-related public policy debates or perform legal abortions. ${ }^{9}$ To model this interaction a dummy variable is created with value 1 in the years in which the policy is applied and zero otherwise and only for the United States, for other countries the dummy variable is always zero. ${ }^{10}$ As one can see from Table $4 \mathrm{~b}$ one cannot trace a discernable influence on the funding for the three channels. Of course, the effect we are testing is rather specific, but an alternative dummy variable approaching the Global Gag Rule - applying the rule that the dummy is 1 in 'Gag years' and zero otherwise, only for non-US countries - did not yield a different conclusion.

\section{Threats of poverty}

To test for the fact that donor behavior is induced by the threat of world-wide poverty, the gap in human development between the donor country and the group of least developed countries is used as a proxy variable. A remarkable result is that the gap does not affect NGO funding or bilateral aid and it affects multilateral funding in a negative way. The fact that the growing gap affects multilateral funding and not the other channels may a result of the fact that funding towards multilateral organizations is part of long-standing national agreements whereas the funding on a bilateral base or towards NGOs is of a more discretionary nature. Hence a move away from multilateral aid towards aid which a donor can control more on a year-to-year base could potentially explain the counterintuitive effects in Table $4 \mathrm{~b}$.

\section{Country characteristics}

There are, of course, sound reasons for this form of specialization across aid categories small countries support multilateral aid organizations more than bilateral aid projects and the situation is completely the reverse for large countries - to come about since there can be substantial economies of scale in making aid work. Using multilateral organizations as the main channel of aid for small countries makes sense. But as we said before there can also be private benefits tied to specific donor options and the benefits are mostly tied to donor preferences.

When we look at the estimation results of Table $4 \mathrm{~b}$ we notice that a number of characteristics of the contributors to multilateral organizations stand out. The fact that organizations like UNFPA and UNAIDS benefit from rich, small countries with a large public sector and a good track record in providing ODA fits the description of top contributors well. 
The Netherlands, Denmark, Norway and Sweden are known for their generous contributions to multilateral reproductive health organizations.

However, the most noteworthy outcomes of the estimation results refer to the religious denomination of countries. As is known from research on private donations to churches and other charity goals (e.g. Iannaccone, 1998), differences between religions play a large role in the level of donations. Religion itself is a clear force in explaining the level of funds across countries. As one can see countries where Catholicism belongs to one of the top two religions in a country exerts a clear negative force with respect to donations to multilateral organizations. This negative sign can be explained because donors have to give up their discretionary power in allocating funds when they donate money to multilateral organizations. Given the strong convictions on issue of family planning (use of condoms, abortion etc.) of the Holy See it stands to reason that Catholic nations are hesitant or averse to this particular aid channel.

However, if the Protestant or Lutheran religion belongs to one the dominant religions in the donor country this negative effect is counterbalanced or even overcompensated. However, we should be careful in putting too much weight on the religious factor and not confuse this element with a country characteristic. It may well be the case that a binding factor in giving development aid plays a dominant role that coincides with the religious dummy variables. It is well-known that the Scandinavian countries fund a relatively high share of ODA or population assistance and these countries happen to be dominated by the Lutheran religion.

The fact that EU members are giving less to multilateral organizations is primarily a result of the fact that the EU as a separate entity also gives aid to reproductive health causes and naturally, an EU member can forego assistance.

\section{Resolving some puzzles}

The previous estimation results showed some anomalies and in this subsection I want to pay closer attention to some of these specific results and test the robustness of some of the previous results. Some of the results were perhaps tied to the fact that the explanatory variable amounted to a share and uniform shocks or dummy variables could not be used to explain changes in shares. As an alternative we will use the level of funds. Both the level of primary funds, split up by aid channels, and GDP are measured in constant US dollars (in 1995 prices). The focus of attention will be on (1) the puzzling result of negative reaction to the threat variable, (2) the absence of an effect of the Mexico City Policy, and an extra subject 
which could not be tested with the shares data is (3) the influence of population conferences on donor behavior. The equation (5) was re-estimated by this time with the dependent variable being the level of funding per aid channel and no longer will the share of income be used as an explanatory variable. Instead, the level of GDP is used as an explanatory variable. To control for the shift in definitions of reproductive health over the sample period, we have used an ICPD (dummy) variable which takes on value 1 from 1995 onwards and for the years till 1995 it has the value zero. The estimation results are presented in Table 5. Before we discuss the empirical puzzles we just want to point out that indeed that ICPD era is marked by a significant shift in funds. And to comment on the most important driving force behind funding one can see clearly the tight relationship between national income development and the generation of primary funds. The total income elasticity is 1.3 and for the underlying aid channels it varies between 1.0 and 1.2. Essentially, this boils down to the message that "what's good for the North, is good for the South". E.g., one can say that a 1 percent increase in real GDP in the donor countries leads to a 1 percent increase in real primary funds flowing to multilateral organizations.

\section{Do donors care about developing world?}

The most puzzling element of Table $3 \mathrm{a}$ is perhaps the negative reaction of donor countries to the gap which exists between the developing world and the donor country itself, as measured by the Human Development Index, which is a composite variable consisting of the level of literacy, life expectancy and GDP per capita. To get a clear picture of what might be at stake the gap variable is split up by the HDI of both the donor and the HDI of the group of least developed countries. In doing so, one can get an idea of which of the two variables are important in driving the results. In Table 5 one can see that it is the human development inside the donor country which is driving the result and not the poor nations of the world. Only in the case of bilateral aid can one see some effect of HDI on donor funding: a decrease of HDI in the LDCs with one percent leads to an increase of bilateral funding with 6.6 percent. Of course, increases in HDI on the donor side are not very likely to show large or sudden fluctuations over time. From 1983 to 2002 the average HDI for all OECD/DAC combined increased from 89.3 to 93.8 .

The fact that the circumstances of the poorest poor in the world affect donations on a bilateral level is to an extent understandable as this aid channel offers governments some discretionary power to do good. With multilateral organizations and NGOs this level of 
Table 5: Explaining Level of Reproductive Health Funds, by Aid Channels, 1983-2002

\begin{tabular}{|c|c|c|c|c|}
\hline & \multicolumn{4}{|c|}{ Level of aid of country $\mathrm{i}$ in: } \\
\hline & $(1)$ & $(2)$ & $(3)$ & $(4)$ \\
\hline & $\begin{array}{c}\text { Total of } \\
\text { primary funds }\end{array}$ & Multilateral & NGO funding & Bilateral funding \\
\hline \multicolumn{5}{|l|}{$\begin{array}{l}\text { Income and state } \\
\text { business cycle }\end{array}$} \\
\hline \multirow[t]{2}{*}{ GDP level } & $1.34 * *$ & $1.01 * *$ & $1.23 * *$ & $1.20 * *$ \\
\hline & $(0.06)$ & $(0.04)$ & $(0.05)$ & $(0.08)$ \\
\hline \multirow[t]{2}{*}{ Unemployment } & $-0.23^{*}$ & $-0.27 * *$ & $-0.35^{*}$ & 0.01 \\
\hline & $(0.10)$ & $(0.10)$ & $(0.15)$ & $(0.22)$ \\
\hline \multicolumn{5}{|l|}{ Interdependency } \\
\hline US Mexico City & -0.05 & -0.06 & -0.09 & -0.01 \\
\hline Policy & $(0.06)$ & $(0.06)$ & $(0.09)$ & $(0.14)$ \\
\hline Average share & 0.19 & -0.09 & -0.07 & -0.30 \\
\hline others $(\mathrm{t}-1)$ & $(0.19)$ & $(0.21)$ & $(0.18)$ & $(0.24)$ \\
\hline \multicolumn{5}{|l|}{ Threat } \\
\hline \multirow[t]{2}{*}{ HDI in LDCs } & -0.22 & 0.66 & -2.42 & $-6.90 * *$ \\
\hline & $(1.20)$ & $(1.00)$ & $(1.57)$ & $(2.58)$ \\
\hline \multirow[t]{2}{*}{ HDI of donor $\mathrm{i}$} & 9.93 & $14.03 * *$ & $24.19 * *$ & $37.25 * *$ \\
\hline & $(6.37)$ & $(4.94)$ & $(6.38)$ & $(10.51)$ \\
\hline \multicolumn{5}{|l|}{$\begin{array}{l}\text { Country } \\
\text { characteristics }\end{array}$} \\
\hline ODA/GDP (excl. & $0.26^{*}$ & $0.59 * *$ & $1.06 * *$ & 0.36 \\
\hline Population funds & $(0.13)$ & $(0.13)$ & $(0.19)$ & $(0.24)$ \\
\hline Left wing & -0.11 & $-0.11 *$ & 0.03 & -0.14 \\
\hline government & $(0.06)$ & $(0.06)$ & $(0.09)$ & $(0.14)$ \\
\hline \multirow[t]{2}{*}{ Income inequality } & $1.59 *$ & -0.09 & $7.52 * *$ & 1.88 \\
\hline & $(0.67)$ & $(0.60)$ & $(0.79)$ & $(1.01)$ \\
\hline \multirow[t]{2}{*}{ Government size } & $1.53 * *$ & $1.97 * *$ & $2.61 * *$ & 0.24 \\
\hline & $(0.47)$ & $(0.49)$ & $(0.64)$ & $(0.80)$ \\
\hline \multirow[t]{2}{*}{ Catholic } & $-0.53 * *$ & $-1.06 * *$ & 0.05 & 0.05 \\
\hline & $(0.17)$ & $(0.16)$ & $(0.21)$ & $(0.25)$ \\
\hline \multirow[t]{2}{*}{ Lutheran } & $3.76^{* *}$ & $2.09 * *$ & $3.89 * *$ & $3.01 * *$ \\
\hline & $(0.33)$ & $(0.34)$ & $(0.40)$ & $(0.45)$ \\
\hline \multirow[t]{2}{*}{ Protestant } & $2.17 * *$ & $1.27 * *$ & $2.26^{* *}$ & $2.56 * *$ \\
\hline & $(0.20)$ & $(0.26)$ & $(0.26)$ & $(0.30)$ \\
\hline \multirow[t]{2}{*}{ EU-member } & $-0.33 * *$ & $-0.38 * *$ & 0.02 & $0.58 *$ \\
\hline & $(0.13)$ & $(0.12)$ & $(0.18)$ & $(0.27)$ \\
\hline \multirow[t]{2}{*}{ ICPD-dummy } & $0.48 * *$ & $0.43 * *$ & $0.37 *$ & $0.80 * *$ \\
\hline & $(0.11)$ & $(0.10)$ & $(0.15)$ & $(0.25)$ \\
\hline Population & 0.03 & 0.02 & -0.03 & 0.04 \\
\hline \multirow{3}{*}{$\begin{array}{l}\text { conrerences } \\
\text { Constant }\end{array}$} & $(0.03)$ & $(0.03)$ & $(0.05)$ & $(0.08)$ \\
\hline & $-35.99 * *$ & $-21.79 * *$ & $-59.19 * *$ & $-37.89 * *$ \\
\hline & $(3.57)$ & $(3.36)$ & $(4.03)$ & $(5.00)$ \\
\hline Loglikelihood & -100.08 & -108.63 & -157.75 & -233.18 \\
\hline $\mathrm{N}$ & 293 & 286 & 235 & 220 \\
\hline
\end{tabular}

(a) FGLS regression with country-specific AR(1) processes and controlling for heteroskedasticity. Standard errors are between brackets below the coefficients, ${ }^{* *}$ denotes significance at $<1 \%$ level; and $*$ denotes significance at $<5 \%$ level. 
control is far more difficult to achieve and apparently others factors come into play in funding patterns towards these channels.

\section{Does the Mexico City Policy affect funding?}

The effects of the so-called Mexico City Policy of the United States could not be traced to the sharing of burdens. Re-estimation of the equation in levels does not change this conclusion. In Table $4 \mathrm{~b}$ a dummy variable was used which had some variation over time for the US but not for the other countries. For a re-estimation of the model in levels a dummy variable is used which takes on the value 1 in 'Gag years' for every country in the sample, and is zero otherwise. The idea behind this formulation is that when the US increases its funding in a specific channel, the other countries will follow suit. The overall effect of the policy is negative, as expected, but not significantly different from zero. To test for the robustness of this conclusion two alternative types of dummies are used in which the dummy values for the US are zero and -1 . None of these dummies changes the conclusion. Of course, the absence of an effect does not constitute a definite verdict on this policy as donor countries can well reshuffle the composition of their aid package in line with the intentions of the Global Gag Rule and still maintain a certain level of funds. The general conclusion of this section is that the Mexico City Policy does not affect the aggregate level of funding.

\section{Do conferences induce opportunism?}

To test the idea of opportunism in funding, I will put Schindlmayer's claim (2004) to the test to see whether population conferences engender opportunistic funding behavior. An opportunist government would raise its level of funding in the year in which a population conference is held, when the focus of the developed world is on the developing world and decrease its funding afterwards. For this purpose we defined a dummy variable that takes on the value zero before time $t$ (the year in which the population conference is held), has the value 1 at time $t$ and for the three subsequent years the dummy value takes on value -1 . The assumption is therefore that during the year in which a population conference is held governments raise their contributions and in the subsequent three years they decrease their contributions. The end result of this strategic behavior is that by shifting resources in time they 'buy' attention. The developing countries will, however, be on the losing side because it simply means that donors diminish their contributions in net terms. The results in Table 5 give an unambiguous verdict about the presence of opportunism: population conferences do not induce opportunistic funding behavior. To test the robustness of this result a number of 
alternative dummy variables were tested capturing the manner in which opportunism could apply to funding behavior by varying the length of years in which funds are decreased after increasing in the year in which the population conference was held. The alternative dummy variables did not overturn the first result and yielded the one and only conclusion that conferences do not affect the timing of funds. There is however, a proviso that needs to be provided in stating this result. The present finding is not necessarily in contrast with the claim made by Schindlmayer (2004) because opportunism can exist for individual countries. The results of Table 5 only suggest that opportunism for the group of countries does not exist.

\section{Conclusions}

Development policy advocates often lament the unfortunate state of affairs that donors never fulfill their commitments. Their solution is often simple: donors should give more money and many a conference is designed to deliver this message. The present paper does not take this line of argument as it assumes that this particular type of market failure is not the exception but the rule. By considering the organization of public goods, and foreign aid in particular, and the specific nature of public goods one might be able to derive policy rules and ambitions which are credible. A situation of underfunding is likely to persist if the global management of aid does not recognize the principal-agent problems underlying collective action failures and if the driving forces of the giving of aid are not acknowledged. The present paper has brought to the fore what driving forces might be relevant in explaining the provision of foreign aid towards family planning and HIV/AIDS programs.

The empirical results of this paper suggest that on an aggregated scale the small donors exploit the large donors, i.e. they contribute more than their fair share. On a more disaggregated scale it appears that small countries pay a relatively larger amount (so-called 'reverse exploitation') in supporting multilateral organizations. However, the disproportionality is not that large and one could even state that each donor country pays more or less its fair share in supporting multilateral organizations. The 'exploitation hypothesis' is confirmed for other channels of aid: large countries prefer bilateral aid and NGOs as their main channel of aid. Strictly speaking, one cannot accuse countries of free riding in matters of bilateral aid as it is by definition a transaction between two partners. However, within the context of the ICPD Programme of action bilateral aid is part of a 'social contract' between OECD countries to carry one third of the global burden of providing reproductive health and HIV/AIDS services and goods. Within this context, all contributions - no matter which 
channel one chooses - are part of the global public effort and apparently large countries pay

disproportionately in supporting NGOs and domestic governments. However, what started out as a question of burden sharing, the estimation results suggest that in order to understand burden sharing more fully, specific country characteristics are important. Especially factors such as religion, the pro-foreign aid stance and government size of a country are good predictors of differences in funding between countries. The most distracting outcome may well be that fact that donors hardly pay attention to the state of development of recipient countries, or to state this with more nuances: the domestic conditions of the donor in determining the level of aid outweigh the conditions of the least developed countries. And perhaps this 'fact' is what outrages most policy advocates and NGOs involved in dealing with reproductive health and HIV/AIDS. However, management by speech, which advocates so abundantly use, will never attain the goals which donors so ambitiously set at conferences and world summits. The most complex of all public goods are global public goods and in that respect we should not expect more funds from simple pleas, no matter how well intended and balanced these pleas are stated. And in that respect examining the full array of issues surrounding the production and management of global public goods (cf. Kaul and Conceicao, 2004) is a more promising road.

\section{References}

Addison, T., M. McGillivray, and M. Odedokun, 2004, Donor Funding of Multilateral Aid Agencies: Determining Factors and Revealed Burden Sharing, World Economy, 173191.

Alesina, A., and D. Dollar, 2000, Who Gives Foreign Aid to Whom and Why?, Journal of Economic Growth, 5: 33-63.

Andreoni, J., and R. Petrie, 2004, Public Goods Experiments without Confidentiality: A Glimpse into Fund-Raising, Journal of Public Economics, 88: 1605-1623.

Barro, R.J., and R.M. McCleary, 2004, International Determinants of Religiosity, NBER Working Paper, no. 10147, Cambridge MA.

Beck, T., Clarke, G., Groff, A, Keefer, Ph. and P. Walsh, 2001, New Tools in Comparative Political Economy: The Database of Political Institutions, World Bank Economic Review, 15: 165-176, and for updates see: http://www.worldbank.org.

Bulatao, R.A., 1998, The Value of Family Planning Programs in Developing Countries, RAND corporation, St. Monica. 
Bulir, A. and A.J. Hamann, 2003, Aid Volatility: An Empirical Assessment, IMF Staff Papers, 50: 64-89.

Gächter, S., and E. Fehr, 1999, Collective Action as a Social Exchange, Journal of Economic Behavior and Organization, 39: 341-369.

Iannaccone, L., 1998, Introduction to the Economics of Religion, Journal of Economic Literature, 36: 1465-1496.

Kaul, I, and R.U. Mendoza, 2004, Advancing the Concept of Public Goods, in: I. Kaul, P.

Conceicao, K. Le Goulven, and R.U. Mendoza (eds.), Providing Global Public Goods, Oxford University Press, Oxford, pp. 78-111.

Olson, M., and R. Zeckhauser, 1966, An Economic Theory of Alliances, Review of Economics and Statistics, 48: 266-279.

Potts, M., J. Walsh, J. McAninch, N. Mizoguchi, and T.J. Wade, 1999, Paying for Reproductive Health Care: What is Needed, and What is Available?, International Family Planning Perspectives, 25: S10-S16.

Sandler, T., 1992, Collective Action - Theory and Applications, Harvester Wheatsheaf, New York.

Sandler, T., and D.G. Arce M., 2002, A Conceptual Framework for Understanding Global and Transnational Public Goods for Health, Fiscal Studies, 23: 195-222.

Sandler, T., and K. Hartley, 2001, Economics of Alliances: The Lessons of Collective Action, Journal of Economic Literature, 39: 869-896.

Schindlmayr, T., 2004, Explicating Donor Trends for Population Assistance, Population Research and Policy Review, 23: 25-54.

Schraeder, P.J., B. Taylor, and S.W. Hook, 1998, Clarifying the Foreign Aid Puzzle: A Comparison of American, Japanese, French and Swedish Aid, World Politics, 50: 294323.

UNESCO, 2000, World Culture Report - Cultural Diversity, Conflict and Pluralism, UNESCO, Paris.

UNFPA, 2003, Financial Resource Flows for Population Activities in 2001, UN/NIDI, The Hague, http:/www.nidi.nl/resflows/rf_download/GPAR2001/GPAR2001.pdf'

Van Dalen, H.P. and M. Reuser (2005), Assessing Size and Structure of Worldwide Funds for Population and AIDS Activities, NIDI, The Hague, www.resourceflows.org. 


\section{ENDNOTES}

${ }^{1}$ Or in the words of the ICPD programme of action: "All countries should take steps to meet the family planning needs of their populations as soon as possible and should, in all cases by the year 2015, seek to provide universal access to a full range of safe and reliable family planning methods and to related reproductive health services which are not against the law." (par. 7.16)

${ }^{2}$ This is also the main reason why Schindlmayer (2004) stops his review of population programs in the year 1995.

${ }^{3}$ We follow at this point by means of analogy the exposition of Sandler and Hartley (2001).

${ }^{4}$ Of course, an alternative strategy is to limit the number of countries which receive aid.

5 All continuous variables are expressed in logarithmic terms.

${ }^{6}$ The estimation model used is Generalized Least Squares with panel specific autoregressive processes of order $1, \mathrm{AR}(1)$ to correct for serial correlation in errors, and a correction for heteroskedasticity, i.e. differences in variance across panel members.

${ }^{7}$ To circumvent arbitrary decisions in pinpointing the change in income inequality over time, these variables are fixed per country and in some cases it is even impossible because only one observation per country is available.

${ }^{8} \mathrm{We}$ have considered alternative religious variables such as the leading religion in a country, the level of religious pluralism or the fact that a country has a state religion (see Barro and McCleary, 2004). The two most dominant religions of a country provided the best fit, although the conclusions do not differ substantially when alternative religious variables are used. The two most dominant religions in a country have been used as our preferred choice of religion variable.

${ }^{9}$ At the International Conference on Population in Mexico City, the U.S. delegation, headed by James Buckley, announces that the United States will no longer fund foreign, non-governmental organizations (NGOs) that provide, refer, counsel, or advocate for abortion. These restrictions were an executive branch policy in effect until 1993, but never became part of the permanent foreign assistance statute. It became known as the Mexico City Policy, and was later dubbed the "Global Gag Rule" by its opponents.

${ }^{10}$ The reason for restricting attention to the United States is that the shares in equation (5) have to sum up to 1 and tracing an effect in one country has to be compensated by others. Therefore, a variable which has a common value for all countries cannot be used. If the Mexico City Policy affects funding policies of individual countries than, e.g., the share of the non-US donors should go up in the 'Gag years' while the share of the US could goes down. 